\title{
Analog tachometer as an indicator motorcycle machine wearing based on moving coil
}

\author{
Dhanis Woro Fittrin Selo Nur Giyatno ${ }^{1, *}$, Tommy Richard Orlando ${ }^{1}$, and Nining Supriatin ${ }^{1}$ \\ ${ }^{1}$ Department of Electrical Engineering and Informatics, Vocational College, Universitas Gadjah Mada
}

\begin{abstract}
As an increasing highly mobility and high traffic, the necessary of motorcycle is highly increasing. The condition makes user ride motorcycle with highly speed in highly frequency. Then, these conditions make motorcycle machine reliability is highly decreasing. Finally, it made machine is run to damage and maintenance cost to be high. Analog tachometer is an electronic instrumentation that proposed to solve these problems. Actually, instrumentation system of tachometer is an electromechanical system. A wire in a control unit is embedded into shaft of crank. Then, magnet in control unit will convert rotary machine energy into electrical energy with d'Arsonval meter. Current sensor and small variable resistor are the kind of sensor that are used in tachometer. Small variable resistor is used for tuning and recalibration. Utilization small variable resistor in tachometer circuit is make calibration and recalibration current sensing of electrical current that rectified by diode. Tachometer for counting rotation per minute (RPM) motorcycle machine is built up. The tachometer has capability to count RPM motorcycle machine 1,000 - 13.000 RPM. The range is reliable as an indicator for user to minimize motorcycle machine wearing.
\end{abstract}

\section{Introduction}

Motorcycle is a popular modern transportation in Indonesia because cheap and high mobility. Therefore, almost people ride with high speed without consider safety and machine wearing. High working intensity make machine reliability decreases. Then, motorcycle machine need high cost to maintenance.

This paper a electronic instrumentation to count the number of motorcycle machine revolution with analog display. Analog tachometer is an electronic instrumentation to count machine revolution based on time period - revolution per minute (RPM). Selection analog display as an RPM measured because for user friendly purpose as utilization analog tachometer for indicator so detailing value is not priority; not for measurement. RPM is a parameter to look process of machine performance.

Reference [1] explains designing and assembling digital tachometer. Reference [2] mentioned that tachometer is used to get information about machine performance. Then, reference [3] explains utilization inertia sensor with generator tachometer. Then, in the reference [4], differential tachometer is designed with arduino as control center to reduce noise. Furthermore, the result of machine revolution is transferred into personal computer. In the reference [5] [6] [7], digital tachometer is used in brushless dc motor testing. Reference [8] [9] use contactless tachometer.
Instrument based electronics circuit such as analog tachometer is used to give weathering or reliability indicator through showing $\mathrm{rpm}$ value of motorcycle machine for user. Furthermore, other researchers are used different method to show machine reliability. Reference [10] used certain algorithm to shown machine reliability, namely machine vibration. Some selection indicators are used to increased diagnosis performance. This diagnose model is conform to implemented for system with profesional user and complex machine that its reliability is affected by many factors. Then, reference [11] used machine vibration as parameter to determine machine fault or the reliability of synchrone rotating machine with permanent magnet. Vibration model is validated by finite element analysis (FEA) conforms to assess machine reliability so the machine fault and isolation fault can be detected and then isolated. Reference [12] explains fault diagnosis for sensor and actuator in the HVAC (heating, ventilation, air conditioner, and cooling) system with temperature as based parameter. Diagnosis process is consisted of 3 steps, namely detecting with distributed linear estimation. Then, local detecting that is consisted of adaptive estimation scheme and decision determining with combinatorial logical decision. Finally, differentiation between actuator fault and sensor fault is done then fault isolation is implemented with neighborhood decision agent. This method is used to diagnose fault which is caused by sensor and actuator or

Corresponding author: dhanisworo@ugm.ac.id 
front end and back end process. Reference [13] explain utilization of active-tolerant control strategy (AFTCS) for octorotor unmanned aerial vehicle (UAV) with considering some motor faults. AFTC have facility to detect error, fault isolated and recovery system. While, parameter for diagnosis are motor velocity and current measurement. When energy losses is detected, algorithm would activated recovery system facility. Reference [14] explains algorithm model or software which can be implemented in industrial manufacture to detect fault process. Alarm in automacy industry is validated as the best solution to be actuator in the method. Reference [15] explain fault detection for gearbox in wind turbine generator. With fault tree analysis, intelligent system is made to detect the machine fault. Qualitative and quantitative analysis are made with $\mathrm{C}++$ in the platform software .Net. Reference [16] explains complexity fault detection process to detect fault of rotating machine because its non-stationery character and non-linear vibration since its operated. Then, machine fault detection which is can extract and classified fault character is proposed. Machine fault detection can detect operation fault and forecasting fault. Reference [17] explains utilization of wavelet analysis to detect machine fault. In the wavelet analysis, every fault can be interpreted as energy losses so fault detection can be done fastly. Reference [18] explains spectrum utilization in the machine fault detection. Differentiation between signal and noise can be done with dividing signal into small signal. Then, power parameter is better to be based parameter to fault detection than voltage or current signal only. Reference [19] explain about complex signal identification in the machine fault detection. Signal sampling toward measurement signal is done correctly. Reference [20] explains utilization of locality constrained linear coding with support vector machine (LLC-SVM) to detect machine fault with vibration as based parameter. LLC-SVM is used to identificate vibration signal and classfified into the kind of fault in the rotating machine.

Based on these researches, there are many information to support our proposed design, namely instrument facility design should be conformed to instrument's function. Detail result is needed if tachometer is used to be instrument measurement. Furthermore detailing and complexity should be reduced when tachometer is used to be an indicator because fast response is priority. Digital output is priority to fulfill tachometer function as an instrument measurement and analog output is used when tachometer's function is an indicator. Arduino as microcontroller is used to control signal output for tachometer

\section{Analog Tachometer}

\subsection{Tachometer}

Tachometer is an instrument to count the number machine revolution based on certain period. Then, tachometer will display the output in the analog or digital number. Motorcycle use tachometer as an indicator machine wearing based on machine revolution.

On the motorcycle machine, tachometer is used to measured direct or indirectly machine revolution based on axis and typically shown the safety range for user. Then, tachometer is controlled by cable moving from control unit which is inserted into machine by electrical method or non-electrical method

\subsection{Moving Coil}

Instrument that work based on moving coil meter is known with d'Arsonval meter. This coil is consisted permanent magnet and coil so an electromagnet phenomenon is happened. Therefore, because of the sensitivity from magnet effect, electromagnet field effect must be avoided from moving coil area. Figure 1 shows physics of moving coil in tachometer.

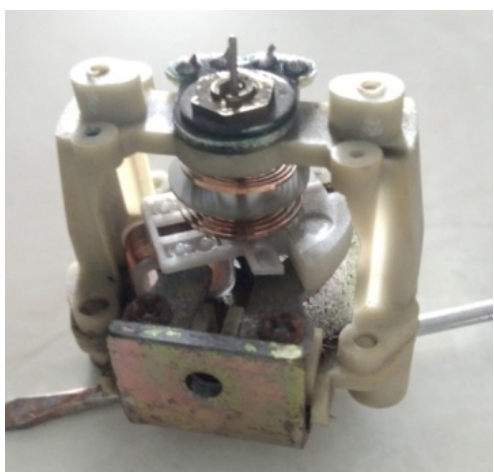

Fig. 1. Moving coil.

\subsection{Electromechanics Concept}

Torque is machine capability to work. Torque parameter is a differential parameter to counting produced energy by rotate machine based on its centered. Therefore, torque is formulated as multiplication between centrifugal force and distance between object and centered or axis. On the combustion motor, axis power is known by measure torque with dynamometer. The principal work of the instrument is giving opposite load with rotation direction until machine revolution 0.00 RPM.

\subsection{Fuel - Mechanics and Mechanics - Thermal Energy Conversion}

There are many component in the motorcycle system that support motorcycle performance. There are needed primary and secondary gear that have connection with centered and gearbox. Fuel oil in motorcycle will converted into thermal and mechanics energy. 
1. Thermal energy is produced by fuel burning and machine compression.

2. Mechanical energy is produced by thermal chamber with caused by machine compression. The kind of energy is used to make primary gear to be move.

3. Primary gear is used to induction process, especially in mechanical energy conversion into thermal energy conversion.

4. Secondary gear is used to reduce gearbox level, especially in thermal energy conversion into mechanical energy.

\section{Design Method}

\subsection{Principal Work of Tachometer}

Voltage input in analog tachometer indicated tachometer ready to count machine revolution. When transducer detects machine revolution, sensor will detect the electrical current that flowed in the circuit. Electrical current in sensor will be rectified by diode then used to make coil to be moved. Furthermore, the coil will make pointer to be move based on the number of machine revolution.

\subsection{Designing Electronic Circuit for Analog Tachometer}

Voltage input in analog tachometer indicated that tachometer is ready to count the machine revolution. Current detected by current sensor will rectify by diode and be calibrated with electronic component. Then, electrical current will make coil to be move and the voltage produced will measured by IC.

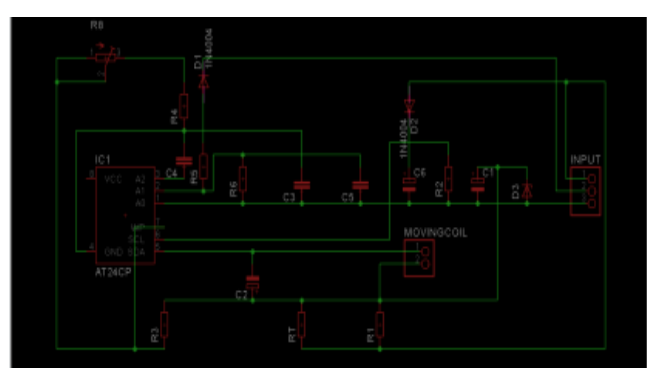

Fig. 2. Electronics circuit of analog tachometer

Furthermore, Figure 2 shows electronic instrumentation circuit of analog tachometer with Eagle software. In this circuit, analog tachometer is designed with 3 cables by different function, namely yellow cable for connecting pulser with diode, black cable for connecting power supply with analog tachometer, and green cable for connecting analog tachometer with ground. Analog tachometer wiring is shown by Figure 3 .

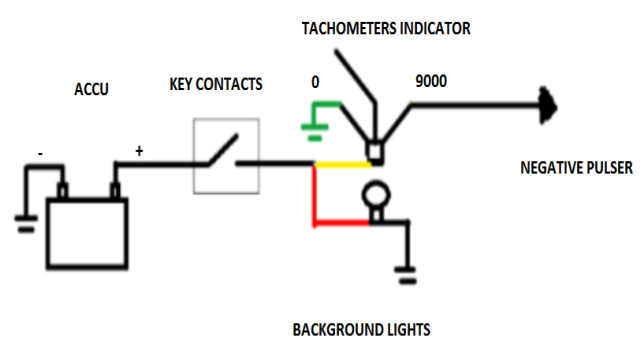

Fig. 3. Analog tachometer wiring

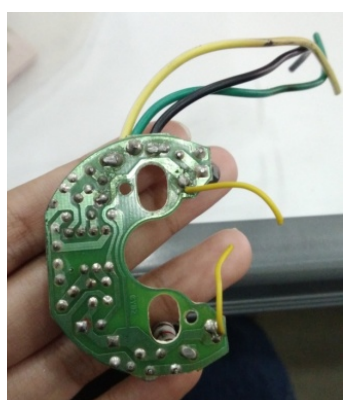

Fig. 4. Electronics circuit board of analog tachometer

\subsection{Designing Analog Tachometer}

Mechanical design for analog tachometer is made after electronic instrumentation circuit is designed. Figure 5, Figure 6, and Figure 7 show prototype planning, analog tachometer without package, and the final product of analog tachometer.

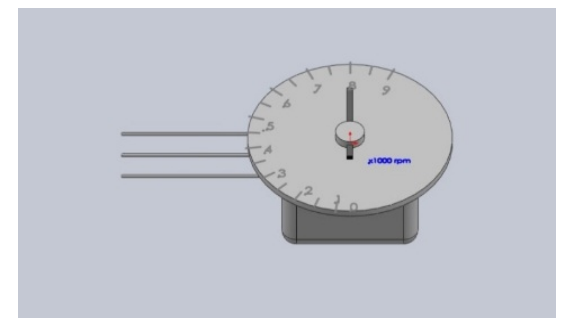

Fig. 5. Proposed design of analog tachometer

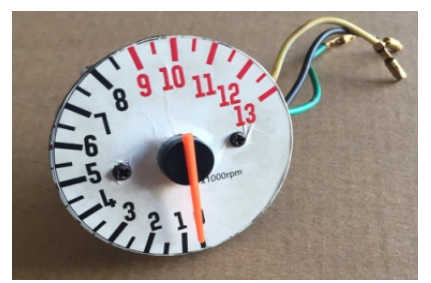

Fig. 6. Analog tachometer without packaging 
Figure 6 shows the result of measurement of analog tachometer without package. The frontend is used to display the result of motorcycle machine revolution. The subsystem is made by acrylic then connected with machine revolution parameter. The parameter have 13 as highend with 1,000 RPM as lowest machine revolution and 13,000 RPM as highest machine revolution.

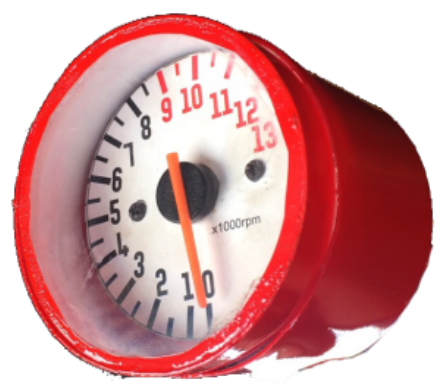

Fig. 7. Analog tachometer witH packaging

Then, pointer is designed moved clockwisely. As an increasing of pointer deviation, the electrical current that readable is higher. Figure 7 shows the product of measurement by analog tachometer. The final step of design method is testing, namely connecting the three cable into motorcycle.

\section{Result and Discussion}

Tachometer is tested with install these electronics circuit into motorcycle. Then, machine revolution is measured when motorcycle was operated. The result shows as follow.

\subsection{Tachometer testing}

Tachometer is designed have machine revolution with range 0 - 13,000 per minute - RPM. Though motorcycle machine is still started to rotate, machine have rotate with 1,000 RPM. It is caused machine must be against machine torque firstly to rotate. Then, when motorcycle machine have machine revolution 1,000 - 3,000 RPM, machine on the stationery or ready to rotate. Therefore, this range indicates transient condition of motorcycle machine. In this range, machine still works normally.

Furthermore, when motorcycle machine have revolution speed 3,000 - 10,000 RPM, machine have optimal condition. At this condition, machine has high performance condition. Therefore, user should have ride motorcycle until 10,000 RPM.

When motorcycle machine have revolution more than 10,000 RPM until 13,000 RPM, machine works inefficient. Therefore, when tachometer shows machine revolution more than $10,000 \mathrm{RPM}$, rotation speed of motorcycle must be decreased. Though the maximum of motorcycle machine revolution is 10,000 RPM, tolerance about 3,000 RPM is given because the difference is needed machine to change its position, namely starting from OFF - ON and ON - OFF. When tachometer have machine revolution more than 13,000 RPM, analog display will move to 0 RPM that indicate user must decrease its rotation speed instantly.

\subsection{Selection Consideration of Analog Display for Tachometer}

Though many indicator panel on the modern vehicle with digital display, tachometer for motorcycle machine performance is designed with analog display. It is caused tachometer for motorcycle has function to give indicator and not to measure so fast response is priority than readability detailing.

Besides that, the trend of machine revolution is dynamically. For example, when motorcycle machine is started, machine will have revolution 1,000 - 3,000 RPM at less than 1 second. Then, when tachometer has digital display, the change of measurement result cannot detect effective.

\subsection{Relationship Between Machine Revolution, Motorcycle Speed, and Fuel Efficiency.}

Motorcycle machine revolution is not connecting with motorcycle speed directly. Motorcycle machine revolution is comparable with work level for same certain machine type and character. Therefore, work level is comparable with fuel consumption.

Motorcycle machine have several gear that effective to use on the certain machine revolution. Because of each gear have different size of gear, the gear torque in these range is different. In the motorcycle machine with manual transmission, utilization of gear is maintained manually with itself. For example, on the motorcycle machine with $2^{\text {nd }}$ gear, machine revolution to get rotation speed $40 \mathrm{~km} /$ hour is needed 3,000 RPM. On the other hand, utilization 3 gear to get same rotation speed, revolution speed that needed 2,000 RPM. With the example, it is known that utilization $2^{\text {nd }}$ gear to get rotation speed $40 \mathrm{~km} /$ hour is needed more fuel. Then, in the motorcycle machine with manual transmission, it will maintain its gear with itself to get every same rotation speed. Though automatic gear selection uses machine revolution parameter as control parameter.

\subsection{Ideal Machine Revolution}

The number of ideal machine revolution for motorcycle machine is depending on motorcycle specification. Usually, motorcycle machine has ideal revolution with range $6,000-10,000 \mathrm{RPM}$. In this range, user is suggested use higher gear level. On the other hand, the regulation is not applied for motorcycle machine with automatic transmission. 
Table 1. Measurement and validation revolution per minute of motorcycle machine.

\begin{tabular}{|c|c|c|c|}
\hline No. & $\begin{array}{c}\text { Revolution } \\
\text { per minute } \\
\text { (RPM) }\end{array}$ & $\begin{array}{c}\text { Motorcycle } \\
\text { speed } \\
\text { (km/hour) }\end{array}$ & Safety level \\
\hline 1. & 4,000 & 30.00 & Safe \\
\hline 2. & 6,000 & 50.00 & Safe \\
\hline 3. & 8,000 & 70.00 & Prone \\
\hline 4. & 9,000 & 80.00 & Prone \\
\hline 5. & 11,000 & 100.00 & Damage \\
\hline 6. & 13,000 & 120.00 & Damage \\
\hline
\end{tabular}

Based on Table 1, it is known that as an increasing machine revolution (indicated with RPM), the speed of motorcycle is more than before. Therefore, as an increasing the number of RPM, the need of fuel is higher.

\section{Conclusion}

Tachometer is an electronic instrumentation used to motorcycle user to keep the machine reliability. Knowing revolution per minute (RPM) of machine, user can anticipate gear level and speed of motorcycle. It is because an increasing the number of RPM of motorcycle machine make an increasing of machine wearing due to machine component friction. An increasing torque of motorcycle, it is needed high level of fuel.

\section{References}

1. M. Rana, S. Sahabuddin, and S. Mondol, "Design and Implementation of a Digital Tachometer," Int. J. Sci. Eng. Technol., vol. 5, no. 1, pp. 85-87, (2016).

2. G. Sachdev, A. Goyal, A. Jain, and J. Surana, "A Study on Vehicle and Counter Measure," Int. J. Eng. Dev. Res., vol. 5, no. 2, pp. 909-921, (2017).

3. K. Iwata, T. Yamamichi, Y. Sugiyama, and T. Kitano, "Train Position Detection System by Means of Inertial Sensors together with a Tachometer Generator," $Q R$ RTRI, vol. 57, no. 4, pp. 293299, (2016).

4. R. Jia, J. O. Yang, H. Lin, and J. Chen, “A Real-Time Differential Anti Strong Interference Tachometer based on Arduino," Int. Conf. Appl. Mech. Electron. Mechatron. Eng. AMEME, pp. 1-6, (2016).

5. S. Nashit, S. Adhikari, S. Farhan, S. Avinash, and A. Gambhire, "Design, Fabrication and Testing of Regenerative Braking Test Rig for BLDC Motor," Int. Res. J. Eng. Technol. IRJET, vol. 3, no. 5, pp. 1881-1884, (2016).

6. N. Mane, P. Mane, K. Sabale, and M. Mokashi, "Design of Multirotor Wind Turbine with Solar Hybrid System," Int. J. Curr. Eng. Technol., no. 6, pp. 1-4, (2016).

7. M. Muchtar, S. Manjang, D. A. Suriamiharja, and M. A. Thaha, "Physical Model Performance of Wave Energy Converter based on Water Mass Gravity Force under Container Shape Variation," Int. J. Sci. Res. IJSR, vol. 5, no. 9, pp. 1627-1630, (2016).

8. A. Bhadani, D. Koladiya, J. Devani, and A. Tahiliani, "Modelling and Controlling of BLDC Motor," Int. J. Adv. Eng. Res. Dev., vol. 3, no. 3, pp. 139-144, (2016).

9. S. Das, P. B. Deb, S. Chakraborty, N. Nag, M. Laha, and P. S. Majumdar, "Contactless Speed Monitoring and Displaying," Int. Res. J. Eng. Technol., vol. 3, no. 12, pp. 876-878, (2016).

10. I. Khelf, L. Laouar, A. M. Bouchelaghem, D. Remond, and S. Saad, "Adaptive fault diagnosis in rotating machines using indicators selection," Mech. Syst. Signal Process., vol. 40, pp. 452-468, (2013).
11. K. Alameh, N. Cite, G. Hoblos, and G. Barakat, "Vibration-based Fault Diagnosis Approach for Permanent Magnet Synchronous Motors," IFAC - Pap. OnLine, vol. 48-21, pp. 1444-1450, (2015).

12. P. M. Papadopoulos, V. Reppa, M. M. Polycarpou, and C. G. Panayiotou, "Distributed Diagnosis of Actuator and Sensor Faults in HVAC Systems," IFAC - Pap. OnLine, vol. 50-1, pp. 42094215, (2017).

13. M. Saied, B. Lussier, I. Fantoni, H. Shraim, and C. Francis, "Fault Diagnosis and Fault-Tolerant Control of an Octorotor UAV using motors speeds," IFAC - Pap. OnLine, vol. 50-1, pp. 5263-5268, (2017).

14. F. L., A. M., and D. A., "A real-time algorithm for fault identification in machining centres," 18th World Congr. Int. Fed. Autom. Control, vol. 44, no. 1, pp. 5201-5206, (2011).

15. Y. Zhi-Ling, W. Bin, D. Xing-Hui, and L. Hao, "Expert System of Fault Diagnosis for Gear Box in Wind Turbine," Syst. Eng. Procedia, vol. 4, pp. 189-195, (2012).

16. W. Li, S. Zhang, and S. Rakheja, "Feature Denoising and NearestFarthest Distance Preserving Projection for Machine Fault Diagnosis," IEEE Trans. Ind. Inform., vol. 12, pp. 393-404, (2016).

17. T. N. Kruglova, "Wavelet analysis for fault diagnosis of electrical machines using current signals," 2nd Int. Conf. Ind. Eng. Appl. Manuf. ICIEAM, pp. 1-5, (2016).

18. N. Hamad, K. F. Brethee, F. Gu, and A. D. Ball, "An investigation of electrical motor parameters in a sensorless variable speed drive for machine fault diagnosis," 22nd Int. Conf. Autom. Comput. ICAC, pp. 329-335, (2016).

19. Z. Du, X. Chen, H. Zhang, H. Miao, Y. Guo, and B. Yang, "Feature Identification with Comprehensive Measurements for Machine Fault Diagnosis," IEEE Trans. Instrum. Meas., vol. 65, no. 5, pp. 977-987, (2016).

20. K. T. Sreekumar et al., "Locality constrained linear coding for fault diagnosis of rotating machines using vibration analysis," Annu. IEEE India Conf. INDICON, pp. 1-6, (2016). 